Check for updates

Cite this: Chem. Sci., 2019, 10, 9591

๑ All publication charges for this article have been paid for by the Royal Society of Chemistry

\section{Expedient access to saturated nitrogen heterocycles by photoredox cyclization of imino- tethered dihydropyridines $\uparrow$}

\author{
Noah B. Bissonnette, (D) J. Michael Ellis, (D) Lawrence G. Hamann \\ and Fedor Romanov-Michailidis (D) *
}

A large proportion of medicinally relevant molecules bear nitrogen and $\mathrm{sp}^{3}$-hybridized carbon functionalities. Overwhelmingly, these atoms are found as part of (hetero)cyclic structures. Despite their importance, synthetic approaches to saturated nitrogen heterocycles are limited to several established stoichiometric alkylation techniques, as well as a few methods involving $\mathrm{C}-\mathrm{H}$ bond activation. The synthetic community remains interested in more general, mild, and sustainable ways to access these motifs. Here we describe a dual-catalyst system composed of an iridium photocatalyst and a lithium phosphate base that is capable of selectively homolyzing the $\mathrm{N}-\mathrm{H}$ bond of 4-alkyl-1,4-dihydropyridines, presumably by proton-coupled-electron-transfer (PCET), and mediating efficient cyclization of the resultant carbon-centered radicals with tethered imines. The outcome of this transformation is access to a broad range of structurally complex nitrogen heterocycles obtainable from simple aldehyde starting materials in a highly chemoselective manner.
Received 11th July 2019

Accepted 26th August 2019

DOI: $10.1039 /$ c9sc03429c

rsc.li/chemical-science piperidines, and piperazines-although substitution can be limited. In addition, catalytic $\mathrm{C}-\mathrm{H}$ activation chemistry has been recently used to prepare piperidine derivatives, ${ }^{8}$ but these methods often require involved substrates and expensive transition-metal catalysts. The limitations imposed by current synthetic methods can increase the difficulty of accessing polysubstituted derivatives of these heterocycles. There remains value in more general, mild, and sustainable approaches to saturated nitrogen heterocycles.

Visible light constitutes an environmentally benign and sustainable source of energy to effect chemical reactivity. ${ }^{9}$ Photocatalysts can remove an electron from organic substrates by harnessing over $60 \mathrm{kcal} \mathrm{mol}^{-1}$ of energy from visible light. In addition, Brønsted bases can catalyze the photo-oxidation of weakly acidic substrates by a process known as proton-coupledelectron-transfer (PCET). PCET involves the simultaneous removal of an electron and a proton from an organic molecule in a single concerted step. ${ }^{10}$

Work by Nishibayashi and Molander demonstrated 4-alkyl1,4-dihydropyridines (DHPs) as latent radical precursors accessed from various aldehydes. ${ }^{11,12}$ The Hantzsch ester moiety can undergo single-electron-transfer (SET) oxidation to the corresponding radical cation I. followed by homolysis of the $\mathrm{C}-\mathrm{C}$ bond, releasing an alkyl radical II. and a pyridine byproduct (Scheme 1). Given the potent hydrogen-bonding ability of Hantzsch esters, ${ }^{13}$ we envisioned oxidation of a DHP moiety under mild conditions by a PCET mechanism combining an iridium photocatalyst and a Brønsted basic counterion $\left(\mathrm{X}^{-}\right) \cdot{ }^{14}$
Celgene Corporation, 200 Cambridge Park Drive, Suite 3000, Cambridge, MA, 02140 , USA. E-mail: fmichailidis@celgene.com; fedorromanov87@gmail.com

$\uparrow$ Electronic supplementary information (ESI) available: Supplementary substrate scope. Supplementary optimizations table. BDFE calculations. Detailed experimental procedures and compound characterization. See DOI: $10.1039 / \mathrm{c} 9 \mathrm{sc} 03429 \mathrm{c}$ 


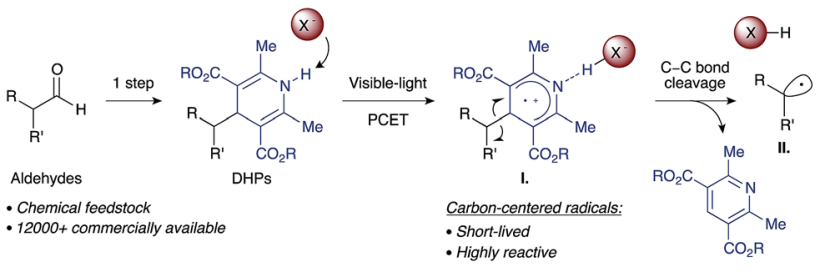

This work:

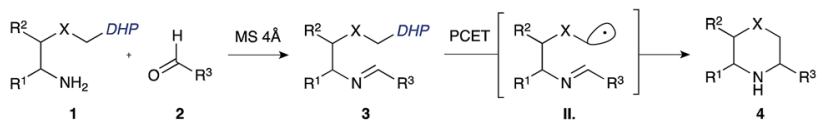

Synthesis of amino-DHP reagents:

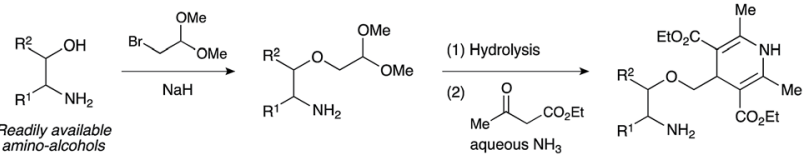

Scheme 1 Synthesis of saturated $\mathrm{N}$-heterocycles by photoredox cyclization of imino-tethered dihydropyridines.

We propose that condensation of an amino-DHP reagent 1 with an aldehyde 2 would give an imino-tethered DHP intermediate 3 that could subsequently photocyclize by a radical PCET mechanism, providing entry to medicinally relevant nitrogen heterocycles such as (thio)morpholines and piperazines 4 (Scheme 1). Earlier reports with tin (SnAP) $)^{15}$ and silicon $(\mathrm{SLAP})^{16}$ radical precursors require toxic reagents, tolerate a narrow substrate scope, or implement harsh reaction conditions. ${ }^{17}$ In contrast, the concerted PCET pathway would allow the use of photocatalysts and bases with redox potentials $\left(E^{\mathrm{ox}}\right)$ and $\mathrm{p} K_{\mathrm{a}}$ values far removed from those of the DHP substrate being activated. ${ }^{18}$ Since radicals may be formed under mild reaction conditions, this was anticipated to afford wider functional group compatibility and overall synthetic utility. Herein, we describe our findings in this endeavour.

At the outset of our studies with the morpholine-forming imino-DHP substrate 3aa, we examined photoredox catalysts that provide higher oxidation potentials in their photoexcited states $\left(E^{* 0 \mathrm{ox}}\right)$ (Table 1). For example, the excited state species of the cationic iridium photocatalyst $\left[\operatorname{Ir}\left(\mathrm{dF}\left(\mathrm{CF}_{3}\right) \mathrm{ppy}\right)_{2}(\mathrm{dtbbpy})\right] \mathrm{PF}_{6}$ $\left(\mathbf{P C} 1, E^{* \mathrm{ox}}+1.21 \mathrm{~V}\right.$ vs. SCE $;^{19,20}$ where $\mathrm{dF}\left(\mathrm{CF}_{3}\right)$ ppy $=2-(2,4-$ difluorophenyl)-5-(trifluoromethyl)pyridine, dtbbpy $=4,4^{\prime}$-ditert-butyl-2,2'-bipyridine) should oxidize the DHP moiety ( $E^{\text {ox }}$ ranging from +1.01 to $+1.23 \mathrm{~V} v$ s. SCE). ${ }^{12,21}$ However, attempted cyclization with this catalyst led to no desired product, unless co-catalytic base was used as an additive. ${ }^{22}$ Among the various bases initially tested, tetrabutylammonium acetate $\left(\mathrm{p} K_{\mathrm{a}}\right.$ of conjugate acid 12 in DMSO) ${ }^{23}$ gave the most promising results ( $25 \%$ yield of product 4 aa, entry 1 ). We reasoned that the low yield was the result of insufficient ability of the reduced form of photocatalyst PC1 $\left(E^{\text {red }}-1.37 \mathrm{~V} v s \text {. SCE }\right)^{19,20}$ to reduce the nitrogen-centered radical and complete the catalytic cycle. ${ }^{24}$ Indeed, switching to a related iridium photocatalyst lacking the $t$-Bu groups on the bipyridyl ligand $\left[\operatorname{Ir}\left(\mathrm{dF}\left(\mathrm{CF}_{3}\right) \mathrm{ppy}\right)_{2}(\mathrm{bpy})\right] \mathrm{PF}_{6}$ $\left(\mathbf{P C} 2, E^{* 0 \mathrm{ox}}+0.97 \mathrm{~V}, E^{\text {red }}-1.23 \mathrm{~V}\right.$ vs. SCE; where bpy $=2,2^{\prime}-$ bipyridine $)^{14,20}$ led to an improved reaction yield (33\%, entry 2$)$.
Table 1 Reaction development ${ }^{a}$
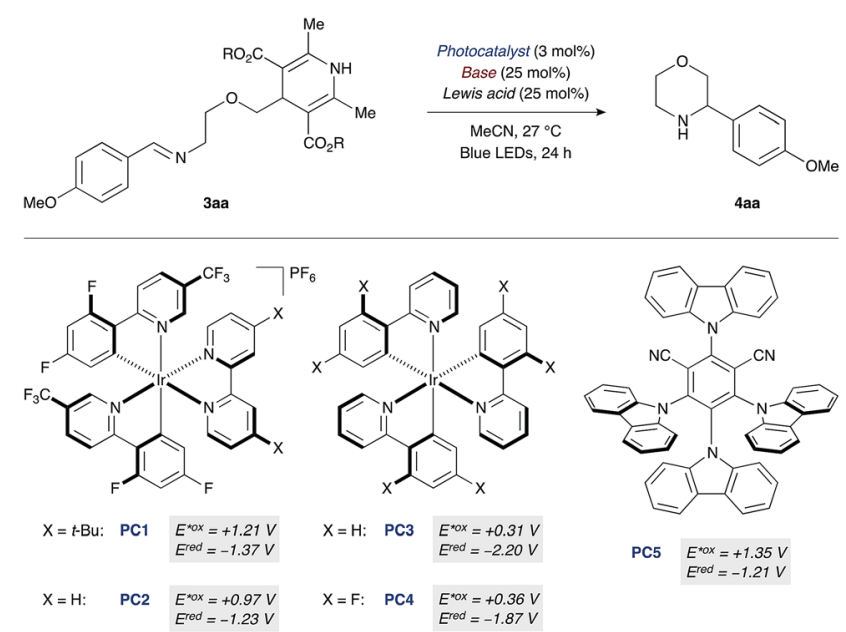

\begin{tabular}{|c|c|c|c|c|}
\hline Entry & Photocat. & Base & Effective $\mathrm{BDFE}^{b}$ & Yield $^{c}(\%)$ \\
\hline 1 & PC1 & {$[\mathrm{AcO}] \mathrm{NBu}_{4}$} & 99 & 25 \\
\hline 2 & PC2 & {$[\mathrm{AcO}] \mathrm{NBu}_{4}$} & 94 & 33 \\
\hline 3 & PC3 & {$[\mathrm{AcO}] \mathrm{NBu}_{4}$} & 78 & 18 \\
\hline 4 & PC4 & {$[\mathrm{AcO}] \mathrm{NBu}_{4}$} & 80 & 20 \\
\hline 5 & PC5 & {$[\mathrm{AcO}] \mathrm{NBu}_{4}$} & 102 & 21 \\
\hline $6^{f}$ & PC2 & {$[\mathrm{AcO}] \mathrm{NBu}_{4}$} & 94 & 39 \\
\hline 7 & PC2 & {$[\mathrm{TFA}] \mathrm{NBu}_{4}$} & 87 & 36 \\
\hline 8 & PC2 & {$[\mathrm{DBP}] \mathrm{NBu}_{4}$} & 84 & 41 \\
\hline $9^{d}$ & PC2 & {$[\mathrm{DBP}] \mathrm{NBu}_{4}$} & 84 & 39 \\
\hline $10^{e}$ & PC2 & {$[\mathrm{DBP}] \mathrm{NBu}_{4}$} & 84 & 45 \\
\hline $11^{f}$ & PC2 & {$[\mathrm{DBP}] \mathrm{NBu}_{4}$} & 84 & 49 \\
\hline 12 & PC2 & {$[\mathrm{DBP}]_{2} \mathrm{Mg}$} & 84 & 48 \\
\hline 13 & PC2 & {$[\mathrm{DBP}] \mathrm{Li}$} & 84 & 51 \\
\hline $14^{g}$ & PC2 & {$[\mathrm{DBP}] \mathrm{Li}$} & 84 & 58 \\
\hline $15^{h}$ & PC2 & {$[\mathrm{DBP}] \mathrm{Li}$} & 84 & 67 \\
\hline $16^{h, i}$ & PC2 & {$[\mathrm{DBP}] \mathrm{Li}$} & 84 & 80 \\
\hline
\end{tabular}

${ }^{a} \mathrm{R}=\mathrm{Et}$, for entries $1-15 .{ }^{b} \mathrm{BDFE}$ in $\mathrm{kcal} \mathrm{mol}^{-1} \cdot{ }^{c}$ Isolated yield of purified product. ${ }^{d}$ With $25 \mathrm{~mol} \%$ of $\mathrm{Bi}(\mathrm{OTf})_{3} .{ }^{e}$ With $25 \mathrm{~mol} \%$ of $\mathrm{Mg}\left(\mathrm{NTf}_{2}\right)_{2} .{ }^{f}$ With $25 \mathrm{~mol} \%$ of LiNTf $_{2} .{ }^{g}$ With $\mathrm{CH}_{2} \mathrm{Cl}_{2}$ as solvent. ${ }^{h}$ With $\mathrm{CH}_{2} \mathrm{Cl}_{2} / \mathrm{TFE} 4: 1$ mixture as solvent. ${ }^{i} \mathrm{R}=\mathrm{i}$-Pr. Ac, acetyl. TFE, 2,2,2-trifluoroethanol. TFA, 2,2,2-trifluoroacetate. DBP, di(n-butyl) phosphate.

Neutral iridium photocatalysts with even lower excited-state oxidation potentials (PC3 and PC4, $E^{* 0 \mathrm{ox}}+0.31$ and $+0.36 \mathrm{~V}$ vs. SCE $)^{20}$ were also investigated. Moderate yields of the desired morpholine 4aa were observed (18\% and $20 \%$, respectively, entries 3 and 4), indicating that strongly oxidizing photocatalysts are not required for successful cyclization given that co-catalytic tetrabutylammonium acetate is present.

To further evaluate effective photocatalyst/base combinations for oxidative DHP cleavage, we made use of a thermodynamic formalism introduced by Mayer ${ }^{25}$ and further elaborated by Knowles ${ }^{\mathbf{1 4}}$ that defines an effective bond strength ("BDFE") for any given oxidant/base pair as a function of the redox potential and $\mathrm{p} K_{\mathrm{a}}$ value of its constituents. We tested the validity of this approach by evaluating the combinations of five photocatalysts PC1-5 and three Brønsted bases of decreasing $\mathrm{p} K_{\mathrm{a}}$ of their conjugate acids $\left(\mathrm{AcO}^{-}>\mathrm{CF}_{3} \mathrm{CO}_{2}{ }^{-}>(n-\mathrm{BuO})_{2} \mathrm{PO}_{2}{ }^{-}\right){ }^{22}$ 
We observed that combinations with "BDFE" values significantly lower than the strength of the $\mathrm{N}-\mathrm{H}$ bond of the Hantzsch ester in substrate 3aa ( $\left.c a .90 \mathrm{kcal} \mathrm{mol}^{-1}\right)^{\mathbf{1 3 b}}$ are not effective catalysts for cyclization. For example, the "BDFE" values for PC3 or PC4 in combination with tetrabutylammonium acetate are 78 and $80 \mathrm{kcal} \mathrm{mol}^{-1}$, respectively, ${ }^{22}$ and the corresponding yields of $4 \mathbf{a a}$ are $18 \%$ and $20 \%$ (entries 3 and 4 ). Similarly, for combinations with very high "BDFE" values (>100 kcal mol ${ }^{-1}$ ), low yields of morpholine $4 \mathbf{a a}$ are obtained. An organic photocatalyst with high oxidation ability, 4CzIPN (PC5, $E^{* \text { ox }}+1.35 \mathrm{~V}$ vs. SCE), ${ }^{26}$ when used in conjunction with tetrabutylammonium acetate leads to only $21 \%$ yield of 4 aa despite a "BDFE" value of $102 \mathrm{kcal} \mathrm{mol}^{-1}$ (entry 5).

However, photocatalyst/base combinations with "BDFE" values approaching or slightly exceeding the N-H BDFE of 3aa result in efficient generation of product 4aa. For example, the "BDFE" values for PC2 in conjunction with either trifluoroacetate $\left[\mathrm{CF}_{3} \mathrm{CO}_{2}\right] \mathrm{NBu}_{4}\left(\mathrm{p} K_{\mathrm{a}} \text { of conjugate acid } 7 \text { in DMSO }\right)^{23}$ or dibutylphosphate $\left[(\mathrm{BuO})_{2} \mathrm{PO}_{2}\right] \mathrm{NBu}_{4}\left(\mathrm{p} K_{\mathrm{a}}\right.$ of conjugate acid 5 in DMSO) ${ }^{23}$ are 87 and $84 \mathrm{kcal} \mathrm{mol}^{-1}$, respectively. This means that PCET activation of DHP substrate 3aa is thermodynamically feasible with these photocatalyst/base combinations. In accord with this, a slight increase in yield is observed experimentally (36\% and 41\%, entries 7 and 8). Notably, iridium complex PC2 $\left(E^{* \text { ox }}+0.97 \mathrm{~V}\right.$ vs. SCE) and dibutylphosphate $\left[(\mathrm{BuO})_{2} \mathrm{PO}_{2}\right] \mathrm{NBu}_{4}\left(\mathrm{p} K_{\mathrm{a}}\right.$ of conjugate acid 5 in DMSO) have an oxidation potential and $\mathrm{p} K_{\mathrm{a}}$ value far removed from those of the DHP substrate $\left(E^{\mathrm{ox}}+1.23 \mathrm{~V} v s\right.$. SCE, $\mathrm{p} K_{\mathrm{a}} 14$ in DMSO). ${ }^{21,23}$ These results are consistent with a PCET mechanism for the oxidation of the Hantzsch ester moiety.

Voltammetric oxidation of 4-alkyl-1,4-dihydropyridines has been described in aprotic ${ }^{21 a}$ and $\operatorname{protic}^{21 b, c}$ media. While at $\mathrm{pH}<$
4 the oxidation process is independent of the $\mathrm{pH}$ of the medium, at $\mathrm{pH}>4$ the process becomes markedly $\mathrm{pH}$ dependent with deprotonation of the $\mathrm{N}-\mathrm{H}$ bond of the Hantzsch ester now being the rate-determining step. Additionally, in the $\mathrm{pH}$-dependent regime, the Hantzsch esters are more easily oxidized than at lower $\mathrm{pH}$ values. Conversely, a $\mathrm{N}$-ethyl Hantzsch ester derivative shows a completely $\mathrm{pH}$-independent oxidation behaviour. To place these observations in the context of our photocatalytic cyclization reaction and further probe the PCET mechanism for DHP cleavage, we ran additional control experiments (Table 2).

Consistent with a PCET mechanism, moderate yields of cyclization product 4aa (33-41\%, entries 1-3) are witnessed for combinations of PC2 and various bases with effective BDFE values in the range of the DHP $\mathrm{N}-\mathrm{H}$ bond strength (ca. $90 \mathrm{kcal} \mathrm{mol}^{-1}$ ). In contrast, almost no product 4 aa is formed when (i) the base is replaced by a non-coordinating $\mathrm{BAr}^{\mathrm{F}}{ }_{4}$ anion (entry 4), (ii) the base is omitted (entry 5), or (iii) a $N$-methyl Hantzsch ester derivative is used as substrate (entry 8). These results suggest that a base and an intact $\mathrm{N}-\mathrm{H}$ bond are both required for efficient photoredox cleavage of the DHP moiety by photocatalyst PC2 $\left(E^{* \text { ox }}+0.97 \mathrm{~V} v s\right.$. SCE). On the other hand, a stronger photooxidant PC5 $\left(E^{* \text { ox }}+1.35 \mathrm{~V} v s\right.$. SCE $)$ that does not necessarily depend on a PCET mechanism to oxidize the Hantzsch ester requires neither a base nor an intact $\mathrm{N}-\mathrm{H}$ bond to promote cyclization (14\% and 17\% yield, entries 6 and 9). Taken together, the results of these control experiments and the published data on the $\mathrm{pH}$ dependency of DHP $E^{\mathrm{ox}}$ potentials are most consistent with a PCET mechanism for the cleavage of the Hantzsch ester in the title reaction. Interestingly, the cyclization with PC5 is more efficient when performed with tetrabutylammonium acetate and an intact $\mathrm{N}-\mathrm{H}$ bond both present $(21 \%$

Table 2 Control experiments to probe the PCET mechanism for DHP cleavage. PMP, para-methoxy phenyl
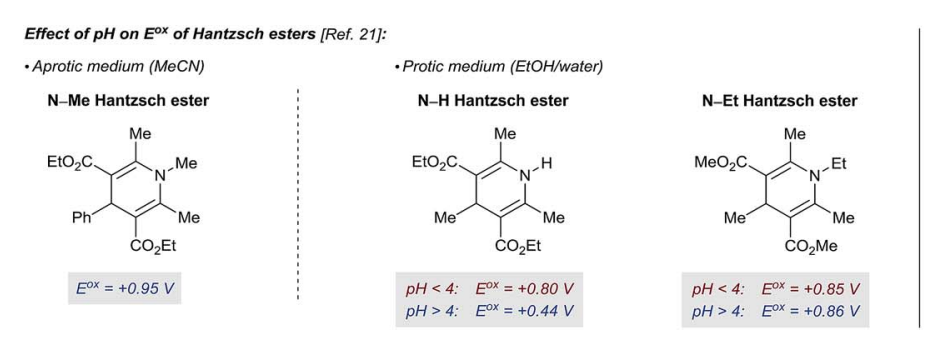

\begin{tabular}{|c|c|c|c|c|c|c|c|}
\hline Entry & $\mathrm{R}$ & Photocat. & $E^{* \mathrm{ox}, a}$ & Base & $\mathrm{p} K_{\mathrm{a}}$ & Effective BDFE $^{b}$ & Yield $^{c}(\%)$ \\
\hline 1 & $\mathrm{H}$ & PC2 & +0.97 & {$[\mathrm{AcO}] \mathrm{NBu}_{4}$} & 12 & 94 & 33 \\
\hline 2 & $\mathrm{H}$ & PC2 & +0.97 & {$[\mathrm{TFA}] \mathrm{NBu}_{4}$} & 7 & 87 & 36 \\
\hline 3 & $\mathrm{H}$ & PC2 & +0.97 & {$[\mathrm{DBP}] \mathrm{NBu}_{4}$} & 5 & 84 & 41 \\
\hline 4 & $\mathrm{H}$ & PC2 & +0.97 & {$\left[\mathrm{BAr}^{\mathrm{F}}{ }_{4}\right] \mathrm{Na}$} & $<1$ & - & $<5$ \\
\hline 5 & $\mathrm{H}$ & PC2 & +0.97 & None & - & - & $<5$ \\
\hline 6 & $\mathrm{H}$ & PC5 & +1.35 & None & - & - & 14 \\
\hline 7 & $\mathrm{H}$ & PC5 & +1.35 & {$[\mathrm{AcO}] \mathrm{NBu}_{4}$} & 12 & 102 & 21 \\
\hline 8 & $\mathrm{Me}$ & PC2 & +0.97 & {$[\mathrm{AcO}] \mathrm{NBu}_{4}$} & 12 & 94 & $<5$ \\
\hline 9 & $\mathrm{Me}$ & PC5 & +1.35 & {$[\mathrm{AcO}] \mathrm{NBu}_{4}$} & 12 & 102 & 17 \\
\hline
\end{tabular}


yield, entry 7). This result implies that hydrogen bonding between the Hantzsch ester and the base is important not only for efficient oxidation of the DHP to its corresponding radical cation but also for subsequent $\mathrm{C}-\mathrm{C}$ bond cleavage (Scheme 1).

From the successful photocatalyst/base combinations tested, we elected to further study the PC2/dibutylphosphate pair. Control reactions omitting either the iridium photocatalyst or visible-light irradiation provided none of the desired cyclization product. $^{22}$ Similarly, reactions run in the absence of the phosphate base resulted in $<5 \%$ conversion of the starting DHP substrate 3aa. Alternatively, adding Lewis acids to the reaction mixture led to interesting results (Table 1). While strong Lewis acids such as $\mathrm{Bi}(\mathrm{OTf})_{3}$ did not have much effect (39\% yield, entry 9), milder Lewis acids such as $\mathrm{Mg}\left(\mathrm{NTf}_{2}\right)_{2}$ or $\operatorname{LiNTf}_{2}$ were found to promote the cyclization ( $45 \%$ and $49 \%$ yield, entries 10 and 11). Most reproducible results are obtained when preforming the dibutylphosphate with the Lewis-acidic cation. Indeed, when using $25 \mathrm{~mol} \%$ of the $\left[(n-\mathrm{BuO})_{2} \mathrm{PO}_{2}\right] \mathrm{Li}$ additive, the desired morpholine 4 aa is recovered in 51\% yield (entry 13 ). Furthermore, we found that the reaction affords better results when (i) carried out in a $4: 1 \mathrm{v} / \mathrm{v}$ mixture of dichloromethane and 2,2,2-trifluoroethanol (67\% yield, entry 15), and (ii) the substrate contains bulky iso-propyl groups on the Hantzsch ester moiety ( $80 \%$ yield, entry 16 ).

To demonstrate the versatility of our one-pot protocol, various aldehydes $\mathbf{2 a - z}, \mathbf{2} \boldsymbol{\alpha}$, and $\mathbf{2} \boldsymbol{\beta}$ (blue colour) were condensed with either morpholine-, thiomorpholine-, or piperazine-forming amino-DHP reagents $\mathbf{1 a}-\mathbf{j}$ (red colour), and then subjected to the photoredox cyclization with visible light irradiation (Scheme 2).

The cyclization tolerates a broad spectrum of substituents and functional groups. For example, benzaldehyde derivatives bearing either electron-withdrawing $\left(\mathrm{CF}_{3}, \mathrm{OCF}_{3}\right.$, and $\left.\mathrm{F}\right)$ or -releasing ( $\mathrm{Me}, \mathrm{MeO}$, and $\mathrm{SiMe}_{3}$ ) substituents at the para position all cyclize well with the morpholine-forming amino-DHP reagent 1a, affording the corresponding heterocyclic products 4aa-4ag in high yields (58-82\%). We were pleased to find that imines 3 derived from heteroaromatic aldehydes also work well in our reaction. These substrates are particularly interesting from a drug discovery perspective, but are challenging to incorporate into redox reactions due to competing off-target oxidation events and non-specific binding of the basic nitrogen atoms to Lewis acids. However, under our mild PCET conditions, a wide array of heteroaromatic substrates are tolerated, ranging from electron-deficient pyridines (3av and 31ß), thienopyridines (3au), isoquinolines (3aj), imidazoles (3ak), pyrazolopyridines (3ax), oxazoles (3as and 3ms), and pyrazoles (3ar and 3hr) to electron-rich furans (3ap), thiophenes (3aq), benzothiophenes (3at and $3 \mathbf{j} \mathbf{t}$ ), indoles (3aw and $3 \mathbf{i} \boldsymbol{\alpha}$ ), indolines (3am), and dihydroimidazothiazoles (3co and 3do). Lastly, imines derived from aliphatic aldehydes cyclize equally well, giving access to pharmacologically relevant products such as chiral glyceraldehyde-derived morpholine 4 ey (58\% yield) or cyclopropyl-substituted piperazine $4 \mathrm{mz}$ (61\% yield). Importantly, the necessity of hydrogen-bonding between the Hantzsch ester moiety and the phosphate base enables chemoselective PCET activation even in the presence of more readily oxidizable

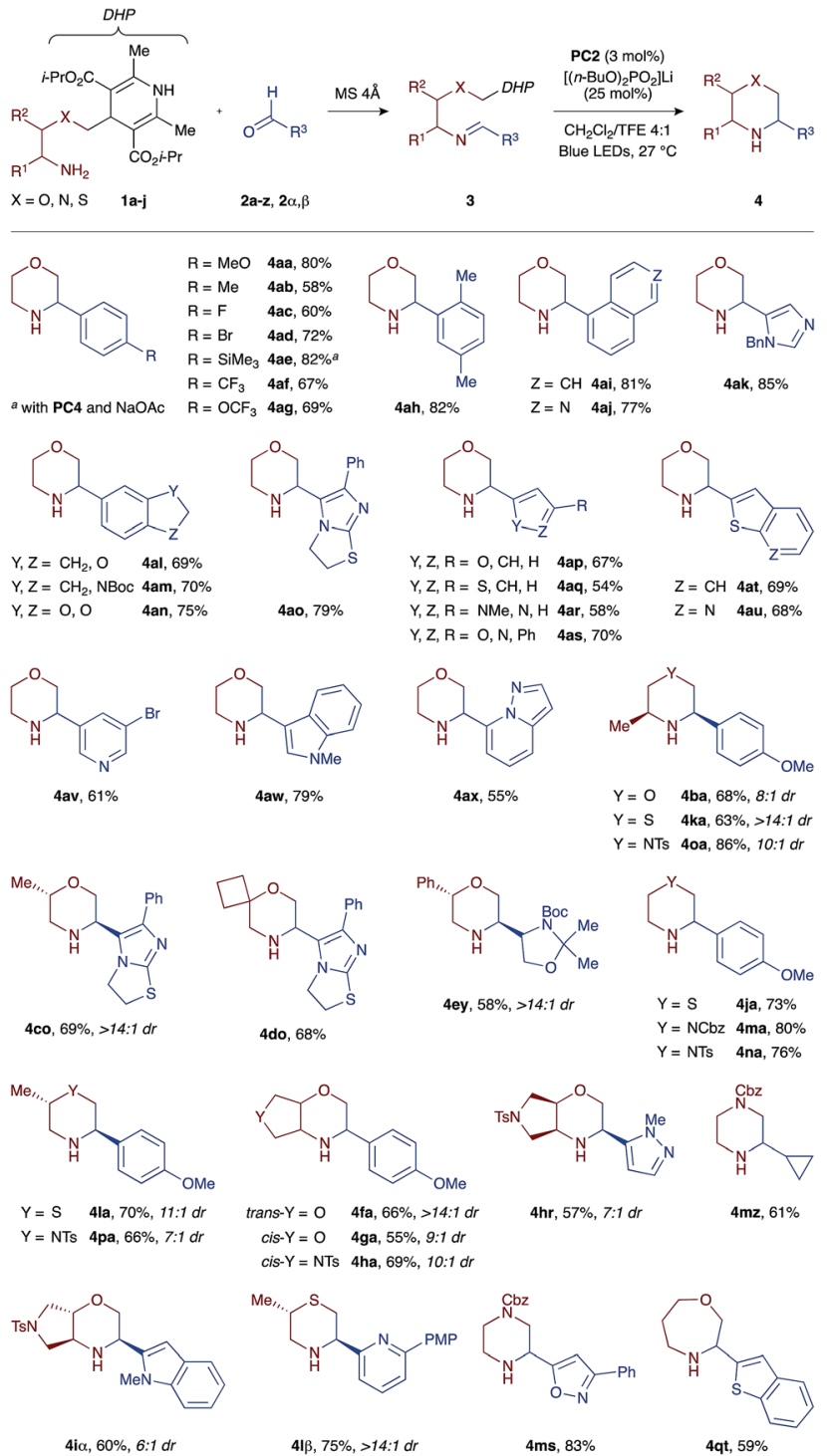

Scheme 2 A representative substrate scope.

groups such as indole (e.g., imines 3aw or $3 \mathbf{i} \alpha$ with $E^{\mathrm{ox}}+1.21 \mathrm{~V}$ vs. SCE).

With respect to the amino-DHP component, various branched tethers are accommodated in the cyclization reaction, including those bearing methyl (1b and 1c) or phenyl groups (1e), spirocycles (1d), and trans- (1f and 1i) or cis-fused bicycles (1g and $\mathbf{1 h})$. The yields of the corresponding morpholine products are mostly high (55-69\%), and excellent diastereoselectivities (up to >14:1 dr) are observed in cases where multiple stereogenic centers are created such as in products 4ba, 4co, 4fa, 4ga, 4ha, 4hr, and 4i $\alpha$. Moreover, the reaction outcome is not restricted to six-membered products, and moderately sized ring systems such as $\mathbf{4 q t}$ can be accessed with equally high efficiency (59\% yield). A more exhaustive list of obtainable heterocyclic products ( $>50$ examples) is compiled in the ESI. $\dagger^{22}$

The generality of our approach was further evaluated by investigating access to saturated nitrogen heterocycles other 
than morpholines. To this end, we devised a set of thiomorpholine- $(\mathbf{1 j}, \mathbf{1 k}$, and $\mathbf{1})$ and piperazine-forming $(\mathbf{1 m}, \mathbf{1 n}, \mathbf{1 0}$, and 1p) amino-DHP reagents that were first condensed with aldehydes $2 \mathbf{a}, 2 \mathbf{s}, \mathbf{2 z}$, and $\mathbf{2} \boldsymbol{\beta}$ and then photocyclized with blue light (Table 1). To our great delight, all of the substrate combinations examined were found to give the expected cyclized products in high yields (63-86\%) and with excellent levels of diastereocontrol (up to $>14: 1 \mathrm{dr}$ ). This is an important finding as it points to the utility of this approach versus previously described methods where the redox potentials of the tin or silicon reagents shift greatly as a function of the heteroatom present in the substrate: $E^{\mathrm{ox}}(\mathrm{O})>E^{\mathrm{ox}}(\mathrm{S})>E^{\mathrm{ox}}(\mathrm{N}) \cdot{ }^{15-17}$ Conversely, because the same DHP moiety is used in all our substrate types, its oxidation potential $\left(E^{\mathrm{ox}}+1.23 \mathrm{~V} v s\right.$. SCE) remains unaffected by the nature of the tethering heteroatom and permits the synthesis of morpholines, thiomorpholines, and piperazines under a single set of catalytic conditions.

As shown in Scheme 3, a plausible redox-neutral photocatalytic cycle involves: (1) PCET quenching of the photoexcited $\operatorname{Ir}(\mathrm{III})^{*}$ species $\left(E^{* \mathrm{Ox}}+0.97 \mathrm{~V}\right)$ by imino-DHP $3\left(E^{\mathrm{ox}}+1.23 \mathrm{~V}\right)$ with help from the Brønsted-basic phosphate anion $\left(\mathrm{x}^{-}, \mathrm{p} K_{\mathrm{a}}\right.$ of conjugate acid 5); (2) $\beta$-scission of the resultant radical-cationic intermediate $\mathbf{I}$. that affords $\alpha$-heteroatom stabilized C-centered radical II., conjugate acid $\mathrm{XH}$, and pyridine byproduct 5; (3) Baldwin-allowed 6-endo-trig cyclization of II. that delivers Ncentered radical III.; and (4) SET-reduction of III. by the $\operatorname{Ir}(\mathrm{II})$ photocatalyst $\left(E^{\mathrm{red}}-1.23 \mathrm{~V}\right)$ followed by proton transfer from acid $\mathrm{XH}$ that furnishes morpholine $\mathbf{4}$ and regenerates the ground-state $\mathrm{Ir}(\mathrm{III})$ photocatalyst as well as the $\mathrm{X}^{-}$counterion.

We reason that the Hantzsch ester moiety in imino-DHP 3 $\left(\mathrm{p} K_{\mathrm{a}} 14\right)$ can form a strong $\mathrm{H}$-bond with dibutylphosphate $\left(\mathrm{p} K_{\mathrm{a}}\right.$ of conjugate acid 5). Although $\mathrm{H}$-bonding of the $\mathrm{N}-\mathrm{H}$ bond is anticipated to lower the potential required for photooxidation of the Hantzsch ester, it will not fully deprotonate the resultant radical cationic intermediate $\mathbf{I}$. Consequently, the nascent radical cation will only be generated when the substrate is associated with the anion. This explains the observed high chemoselectivity of our method. Indeed, the employed

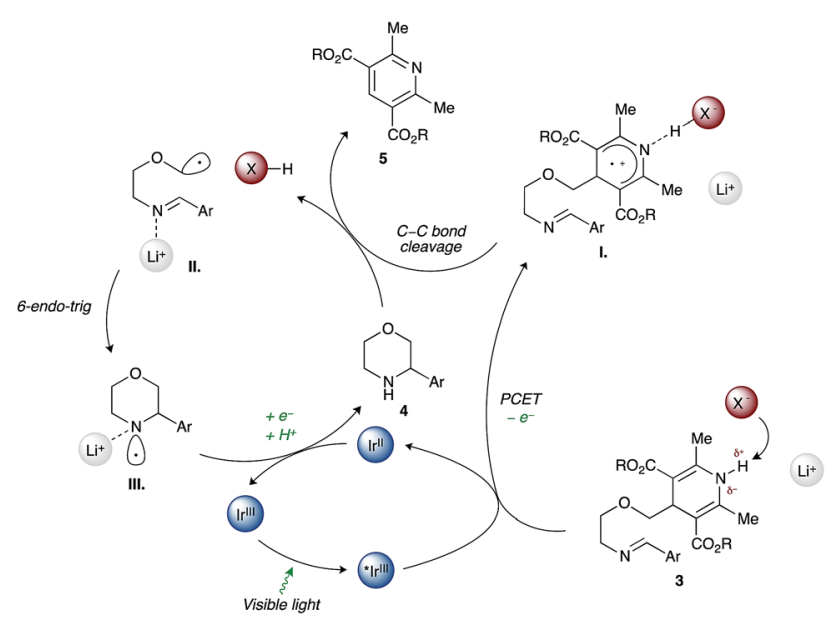

Scheme 3 Postulated catalytic cycle. photocatalyst/base dual-catalyst system is reluctant to oxidizing other redox-labile functional groups present in substrates given that they do not have $\mathrm{N}-\mathrm{H}$ bonds of sufficient acidity. Furthermore, we believe that the Lewis-acidic lithium cation coordinates to the $\mathrm{N}$-centered radical III. leading to its stabilization and a concomitant decrease of its reduction potential relative to the uncoordinated $\mathrm{N}$-centered radical. ${ }^{27}$ This in turn renders reduction of III. by the $\operatorname{Ir}(\mathrm{II})$ photocatalyst $\left(E^{\mathrm{red}}-1.23 \mathrm{~V}\right)$ more facile.

Nitrogen heterocycles are among the most abundant structural components of pharmaceuticals. For example, of the top 200 brand name commercial medicines in 2014, 116 contain a nitrogen heterocycle. ${ }^{3 a}$ We have developed a one-pot approach to saturated nitrogen heterocycles that harnesses energy from visible light to cleave 4-alkyl-1,4-dihydropyridines by a unique PCET mechanism. Cleavage is followed by cyclization of the resultant carbon-centered radical with a tethered imine, giving heterocyclic products. Our mild protocol is characterized by a remarkably broad substrate scope and high functional group tolerance. The concise assembly of a variety of these heterocycles should allow desirable properties such as solubility, permeability, and metabolic stability, to be built into lead series, ultimately increasing the pace of drug discovery.

\section{Author contributions}

This project was conceived and initiated by FRM. Optimization of the reaction conditions, the synthesis and characterization of starting materials and products was performed by NBB with assistance from FRM. The manuscript was drafted by FRM and proofread by FRM, NBB, LGH, and JME. The ESI was drafted by NBB and proofread by FRM, NBB, LGH, and JME.

\section{Conflicts of interest}

There are no conflicts to declare.

\section{Acknowledgements}

The authors would like to acknowledge Dr Geraint Davies and Dr Kurt Armbrust for helpful discussions.

\section{Notes and references}

1 M. S. Butler, A. A. Robertson and M. A. Cooper, Nat. Prod. Rep., 2014, 31, 1612.

2 (a) P. A. Clemons, N. E. Bodycombe, H. A. Carrinski, J. A. Wilson, A. F. Shamii, B. K. Wagner, A. N. Koethler and S. L. Schreiber, Proc. Natl. Acad. Sci. U. S. A., 2010, 107, 18787; (b) D. Morton, S. Leach, C. Cordier, S. Warriner and A. Nelson, Angew. Chem., Int. Ed., 2009, 48, 104.

3 (a) E. Vitaku, D. T. Smith and J. T. Njardarson, J. Med. Chem., 2014, 57, 10257; (b) S. D. Roughley and A. M. Jordan, J. Med. Chem., 2011, 54, 3451; (c) J. S. Carey, D. Laffan, C. Thomson and M. T. Wiliams, Org. Biomol. Chem., 2006, 4, 2337.

4 (a) F. Lovering, J. Bikker and C. J. Humblet, J. Med. Chem., 2009, 52, 6752; (b) F. Lovering, MedChemComm, 2013, 4, 515. 
5 D. G. Brown and J. Boström, J. Med. Chem., 2016, 59, 4443.

6 T. Cernak, K. D. Dykstra, S. Tyagarajan, P. Vachal and S. W. Krska, Chem. Soc. Rev., 2016, 45, 546.

7 (a) S. A. Worlikar, T. Kesharwani, T. Yao and R. C. Larock, J. Org. Chem., 2007, 72, 1347; (b) T. J. A. Graham and A. G. Doyle, Org. Lett., 2012, 14, 1616; (c) S.-X. Liu, C.-M. Jia, B.-Y. Yao, X.-L. Chen and Q. Zhang, Synthesis, 2016, 48, 407; (d) C. C. Malakar, D. Schmidt, J. Conrad and U. Beifuss, Org. Lett., 2011, 13, 1972; (e) R. K. Orr, L.-C. Campeau, H. R. Chobanian, H. M. McCabe Dunn, B. Pio, C. W. Plummer, A. Nolting and R. T. Ruck, Synthesis, 2017, 49, 657; (f) T. Azuma, A. Murata, Y. Kobayashi, T. Inokuma and Y. Takemoto, Org. Lett., 2014, 16, 4256; (g) Y.-L. Du, Y. Hu, Y.-F. Zhu, X.-F. Tu, Z.-Y. Han and L.-Z. Gong, J. Org. Chem., 2015, 80, 4754; $(h)$ M. Yan, T. Jin, Q. Chen, H. E. Ho, T. Fujita, L.-Y. Chen, M. Bao, M.-W. Chen, N. Asao and Y. Yamamoto, Org. Lett., 2013, 15, 1484; (i) N. Gandhamsetty, S. Park and S. Chang, Synlett, 2017, 28, 2396.

8 (a) F. Romanov-Michailidis, K. F. Sedillo, J. M. Neely and T. Rovis, J. Am. Chem. Soc., 2015, 137, 8892; (b) I. S. Hassan, A. N. Ta, M. W. Danneman, N. Semakul, M. Burns, C. H. Basch, V. N. Dippon, B. R. McNaughton and T. Rovis, J. Am. Chem. Soc., 2019, 141, 4815.

9 J. Twilton, C. Le, P. Zhang, M. H. Shaw, R. W. Evans and D. W. C. MacMillan, Nat. Rev., 2017, 1, 1.

10 (a) J. M. Mayer, Annu. Rev. Phys. Chem., 2004, 55, 363; (b) D. R. Weinberg, C. J. Gagliardi, J. F. Hull, C. F. Murphy, C. A. Kent, B. C. Westlake, A. Paul, D. H. Ess, D. G. McCafferty and T. J. Meyer, Chem. Rev., 2012, 112, 4016; (c) H. G. Yayla and R. R. Knowles, Synlett, 2014, 25, 2819.

11 K. Nakajima, S. Nojima, K. Sakata and Y. Nishibayashi, ChemCatChem, 2016, 8, 1028.

12 A. Gutiérrez-Bonet, C. Remeur, J. K. Matsui and G. A. Molander, J. Am. Chem. Soc., 2017, 139, 12251.

13 (a) U. Eisner and J. Kuthan, Chem. Rev., 1972, 1, 1; (b) A. I. Meyers and D. M. Stout, Chem. Rev., 1982, 82, 223; (c) R. Fossheim, A. Joslyn, A. J. Solo, E. Luchowski, A. Rutledge and D. J. Triggle, J. Med. Chem., 1982, 25, 126; (d) S. Goldman, L. Born, S. Kazda, B. Pittel and M. Schramm, J. Med. Chem., 1990, 33, 1413.
14 G. J. Choi and R. R. Knowles, J. Am. Chem. Soc., 2015, 137, 9226.

15 (a) C.-V. T. Vo, G. Mikutis and J. W. Bode, Angew. Chem., Int. Ed., 2013, 52, 1705; (b) W.-Y. Siau and J. W. Bode, J. Am. Chem. Soc., 2014, 136, 17726.

16 S.-Y. Hsieh and J. W. Bode, ACS Cent. Sci., 2017, 3, 66.

17 (a) M. U. Luescher, C.-V. T. Vo and J. W. Bode, Org. Lett., 2014, 16, 1236; (b) S.-Y. Hsieh and J. W. Bode, Org. Lett., 2016, 18, 2098; (c) M. K. Jackl, L. Legnani, B. Morandi and J. W. Bode, Org. Lett., 2017, 19, 4696; (d) C. Jindakun, S.-Y. Hsieh and J. W. Bode, Org. Lett., 2018, 20, 2071.

18 (a) E. C. Gentry and R. R. Knowles, Acc. Chem. Res., 2016, 49, 1546; (b) L. Q. Nguyen and R. R. Knowles, ACS Catal., 2016, 6, 2894.

19 (a) J. D. Slinker, A. A. Gorodetsky, M. S. Lowry, J. Wang, S. Parker, R. Rohl, S. Bernhard and G. G. Malliaras, J. Am. Chem. Soc., 2004, 126, 2763; (b) M. S. Lowry, J. I. Goldsmith, J. D. Slinker, R. Rohl, R. A. Pascal, G. G. Malliaras and S. Bernhard, Chem. Mater., 2005, 17, 5712.

20 K. Teegardin, J. I. Day, J. Chan and J. Weaver, Org. Process Res. Dev., 2016, 20, 1156.

21 (a) J. Stradins, J. Ogle, V. Kadysh, L. Baumane, R. Gavars and G. Duburs, J. Electroanal. Chem., 1987, 226, 103; (b) J. Arguello, L. J. Nunez-Vergara, J. C. Sturm and J. A. Squella, Electrochim. Acta, 2004, 49, 4849; (c) C. LopezAlarcon, L. J. Nunez-Vergara and J. A. Squella, Electrochim. Acta, 2003, 48, 2505.

22 See the ESI† for details.

23 F. G. Bordwell, Acc. Chem. Res., 1988, 21, 456.

24 (a) H. Uoyama, K. Goushi, K. Shizu, H. Nomura and C. Adachi, Nature, 2012, 492, 234; (b) J. Luo and J. Zhang, ACS Catal., 2016, 6, 873.

25 (a) J. J. Warren, T. A. Tronic and J. M. Mayer, Chem. Rev., 2010, 110, 6961; (b) C. R. Waidmann, A. J. Miiler, C. W. A. Ng, M. L. Scheuermann, T. R. Porter, T. A. Tronic and J. M. Mayer, Energy Environ. Sci., 2012, 5, 7771.

26 N. A. Romero and D. A. Nicewicz, Chem. Rev., 2016, 116, 10075.

27 (a) M. Jonsson, D. D. M. Wayner and J. Lusztyk, J. Phys. Chem., 1996, 100, 17539; (b) U. Wille, G. Heuger and C. Jargstorff, J. Org. Chem., 2008, 73, 1413. 